\title{
Hyperbaric Storage at Room Temperature for Fruit Juice Preservation
}

\section{Laura Otero $\mathbb{D}$}

MALTA Consolider Team, Institute of Food Science, Technology and Nutrition (ICTAN-CSIC) c/José Antonio Novais, 10, 28040 Madrid, Spain; 1.otero@ictan.csic.es; Tel.: +34-91-544-5607

Received: 20 May 2019; Accepted: 4 July 2019; Published: 2 August 2019

\begin{abstract}
Hyperbaric storage is an innovative preservation method that consists of storing food under pressure, either at room or at low temperature, for time periods of days, weeks, or months. Recent scientific literature shows that hyperbaric storage at room temperature (HS-RT) could be an efficient method for fruit juice preservation. Depending on the level applied, pressure can inhibit and even inactivate the endogenous microflora of the fresh juice, while properly preserving other organoleptic and quality indicators. Even though the method has not yet been implemented in the food industry, its industrial viability has been evaluated from different points of view (product quality, consumer acceptation, vessel design, economic, or environmental, among others). The results reveal that HS-RT is effective in extending the shelf-life of both acidic and low-acidic fruit juices. Moreover, the energetic costs and the carbon footprint of HS-RT are considerably lower than those of refrigeration, therefore, HS-RT could be a reliable and environmentally friendly alternative to conventional cold storage. However, before industrial implementation, much more research is needed to clarify the effects of the storage conditions on the agents that cause fruit juice deterioration.
\end{abstract}

Keywords: hyperbaric storage; high pressure; food preservation; fruit juice

\section{Introduction}

The global fruit juice market reached a volume of 45.4 billion liters in 2018 and almost a quarter of this total volume was consumed in the EU [1]. Here, the per capita consumption of chilled juices has been continuously growing over the last five years, probably because many consumers perceive chilled products as healthier and more natural than ambient offerings [2]. However, the increasing demand of chilled products can have negative environmental consequences as food refrigeration is directly implicated in global warming and climate change [3,4]. It causes both direct greenhouse gas (GHG) emissions from the manufacture and direct loss of refrigerants as well as indirect GHG emissions from the energy use required to maintain the cold chain. Thus, food refrigeration is considered to be responsible for approximately $1 \%$ of the total global GHG emissions [5]. In the last decades, many strategies to reduce these emissions have been tested such as using refrigerants of low global warming potential, improving the insulation, design, and location of chilling and freezing facilities, or applying clean energy technologies, among others [5], but currently, food refrigeration still poses serious problems of sustainability. Therefore, to fight against climate change, novel, environmentally friendly storage methods with reduced energy requirements that are able to guarantee food safety and quality are urgently needed to replace refrigeration.

Recently, hyperbaric storage at room temperature (HS-RT) has been proposed as a potential alternative to refrigeration for food preservation. This novel storage method must not be confused with high-pressure processing that, nowadays, is a well-established technology in the food industry. In high-pressure processing, foods are treated at high pressure (about 300-700 MPa) for brief time periods, generally shorter than $10 \mathrm{~min}$. The usual objective is to extend their shelf-life during the 
subsequent cold storage at atmospheric pressure. In contrast, in hyperbaric storage, the product is not treated at high pressure for some minutes, but stored under moderate pressure, usually not higher than $100 \mathrm{MPa}$, during the whole storage period, that is, days, weeks, or even months. The pursued aim is to use pressure as a limiting factor for food deterioration, just like low temperature in refrigeration. As food is preserved at room temperature, the only energy consumption is produced at the beginning of storage, during compression, because no additional energy is required to maintain the product under pressure for long times. Therefore, this system can involve considerable energy savings when compared with other food storage methods such as freezing or refrigeration. Obviously, hyperbaric storage can also be performed at low temperature, but in this case, energy costs would be increased.

Even though hyperbaric storage was first proposed as a food preservation method in 1977 [6], this technique has not really been explored until this century most likely because many doubts existed about its potential viability at an industrial scale. However, after the successful implementation of high-pressure processing in the food industry, the interest in hyperbaric storage has been revived. In 1997 and 2000, two patents were published [7,8] that described how a huge variety of raw and cooked foods and food ingredients could be preserved under pressure at $18-23^{\circ} \mathrm{C}$. Next, papers about hyperbaric storage at room temperature started to appear in the scientific literature, especially in this last decade. They proved that HS-RT was more efficient than conventional refrigeration for the preservation of not only fruit juices [9], but also meat [10-12] and milk products [13,14] and ready-to eat pre-cooked foods $[15,16]$. Despite this, HS-RT can be considered to be in its initial phase and, in fact, industrial equipment specifically designed for hyperbaric storage still has not been commercialized.

In this review, hyperbaric storage at room temperature is presented as a novel and environmentally friendly method for fruit juice preservation. Data from the existing literature have been gathered to critically evaluate the viability of the method from a multiple points of view, covering as many aspects as possible from juice safety and quality to consumer acceptability, equipment design, economic, and environmental issues. In this way, this review contributes to offering sustainable solutions to the food industry for fruit juice preservation.

\section{Effect of Hyperbaric Storage on Agents Responsible for Juice Deterioration}

It is obvious that the effectivity of HS-RT for fruit juice preservation depends on the effects that pressure produces on all of the agents responsible for juice deterioration. Among them, microbial agents are frequently considered the major concern, but enzymatic and chemical deterioration can also play a significant role in juice spoilage [17]. In the next subsections, the available information about the activity of all of these agents under pressure is presented. Microbial activity under pressure is assessed by comparing the microbial loads before and immediately after HS-RT, while enzymatic and chemical activities are evaluated by comparing the amount of either the reagents or the reaction products before and after HS-RT.

\subsection{Microbial Load}

Many papers in the literature have revealed that HS-RT is an effective method to extend the microbiological shelf-life of fruit juices over that achieved by conventional refrigeration $[9,18-20]$. For example, Lemos, Ribeiro, Fidalgo, Delgadillo, and Saraiva [18] reported that HS-RT at $75 \mathrm{MPa}$ allowed for the shelf-life of watermelon juices to be extended for at least 21 days, while in conventional refrigeration, the product was completely spoilt after seven days. The effectiveness of HS-RT in hampering the cell-proliferating ability of microorganisms depends on several factors such as the storage pressure and time, the product characteristics, or the specific microorganisms present in the juice microbiota, among others.

The pressure level applied during hyperbaric storage plays a decisive role in the effects observed in the microflora of fruit juices. It is well-known that relatively low pressures $(<50 \mathrm{MPa})$ are nonlethal for most mesophilic microorganisms, but affect some cellular processes such as motility, substrate transport, nutrient uptake, or cell division and growth [21-23]. However, most microorganisms can adapt 
themselves to these pressures and, although the lag phase frequently becomes longer as pressure increases, they can still proliferate [24]. When pressure is increased, DNA replication, translation, and transcription can be affected, and at 100-200 MPa and higher, microbial viability can be significantly reduced through multi-target inactivation mechanisms [21-23]. Therefore, depending on the pressure employed, HS-RT can not only slow down the microbial growth as refrigeration does, but also produces some damage in the microorganisms, resulting in microbial inactivation. For example, Bermejo-Prada et al. [25] observed that after one day of storage at $25 \mathrm{MPa}$, the initial counts of total aerobic mesophiles (TAM) and lactic acid bacteria (LAB) in strawberry juice remained almost invariable, while yeasts and molds (YM) decreased slightly. In contrast, storage at $50 \mathrm{MPa}$ produced a slight decrease not only in the YM counts, but also in the TAM and LAB counts, while at 100 and $200 \mathrm{MPa}$, significant TAM, LAB, and YM reductions of 1.4, 1.6, and $1.0 \log _{10}$ units and of 3.6, 3.6, and $3.1 \log _{10}$ units were detected, respectively.

Moreover, microbial growth during hyperbaric storage is also affected by the storage time. In general, the longer the storage time, the greater the microbial damage produced $[18,19,25,26]$. Thus, Lemos, Ribeiro, Fidalgo, Delgadillo, and Saraiva [18] stored watermelon juices at $75 \mathrm{MPa}$ and room temperature and, after three and 21 days of storage, they observed reductions close to 1 and $2 \log _{10}$ units, respectively, in both the total aerobic mesophiles and total aerobic psychrophiles. However, it is important to note that at low storage pressures, microbial growth can occur after certain lag phase under pressure as previously mentioned. For example, Bermejo-Prada, López-Caballero, and Otero [25] observed that storage at $25 \mathrm{MPa}$ for 1-10 days completely inhibited TAM, LAB, and YM growth in strawberry juice, but after 15 days of storage, the microbial load can be increased. Similar findings were described by Pinto, Moreira, Fidalgo, Santos, Vidal, Delgadillo, and Saraiva [19]. Thus, they stored watermelon juice at $50 \mathrm{MPa}$ and room temperature and reported no significant increase in the total aerobic mesophiles and psychrophiles after four days of storage. However, after seven days, both counts increased by about $2 \log _{10}$ units and reached values over the acceptability limit ( $>6 \log _{10} \mathrm{CFU} / \mathrm{mL}$ ). The elimination of the pressure labile microbiota at the beginning of the storage could favor the growth of pressure-resistant populations and contribute to the microbial growth observed at the end of storage in the above examples. Moreover, sublethal stresses could induce the expression of cell repair systems [27] and, therefore, an adaptation of some strains to stress could take place during long storage at relatively low pressures.

The intrinsic product characteristics are also a main factor that affects the effectiveness of HS-RT in preventing microbial spoilage. Some attributes such as the product composition, water activity, or $\mathrm{pH}$ can strongly impact on the effects observed after hyperbaric storage. For example, unlike in strawberry juice $(\mathrm{pH}=3.3)$, HS-RT at $25 \mathrm{MPa}$ did not slow down the growth of the natural microbiota in melon $(\mathrm{pH}=5.7)$ and watermelon $(\mathrm{pH}=5.8)$ juices [28,29], and pressures of $50 \mathrm{MPa}$ and $75 \mathrm{MPa}$ were needed to either reduce or completely stop microbial growth in these products $[18,19,28,29]$. The greater sensitivity to pressure observed in strawberry juice compared with melon and watermelon juices could be related to the low $\mathrm{pH}$ of this product. In this sense, Matsumura et al. [30] showed that pressure markedly narrowed the $\mathrm{pH}$ ranges for the growth of a variety of bacteria. Moreover, different authors in the literature have shown that as $\mathrm{pH}$ is lowered, most microbes become more susceptible to high-pressure inactivation [31-33].

Treatments applied to juices prior to HS-RT can also have an impact on microbial stability during hyperbaric storage. Thus, Segovia-Bravo, Guignon, Bermejo-Prada, Sanz and Otero [9] observed that the initial microbial load of frozen-thawed strawberry juice was reduced by more than $2 \log _{10}$ units after 15 days of HS-RT at $25 \mathrm{MPa}$. At the end of storage, microbial levels were below the detection limit ( $10 \mathrm{CFU} / \mathrm{mL}$ for TAM and $100 \mathrm{CFU} / \mathrm{mL}$ for $\mathrm{YM}$ ) and remained stable for at least 15 additional days at atmospheric pressure and $5{ }^{\circ} \mathrm{C}$. In contrast, Bermejo-Prada, López-Caballero, and Otero [25] reported that in freshly squeezed strawberry juice, HS-RT at $25 \mathrm{MPa}$ retarded microbial growth when compared to conventional cold storage, but could not completely avoid microbial proliferation. These results 
clearly indicate that microbial stability during HS-RT could be enhanced by the stress of the previous freeze-thaw treatment.

All the above results show that hyperbaric storage at room temperature can be an effective method to inhibit the growth of the endogenous microflora in fruit juices. To gain the first insight into the effects of HS-RT on pathogenic microorganisms, Pinto, Moreira, Fidalgo, Santos, Vidal, Delgadillo, and Saraiva [19] inoculated two specific microorganisms, Listeria innocua (ATCC 33090) and Escherichia coli (ATCC 25992), as surrogates for pathogen L. monocytogenes and pathogenic E. coli, in watermelon juice (3-4 $\log _{10} \mathrm{CFU} / \mathrm{mL}$ ) and stored it for 10 days at 50, 75, or $100 \mathrm{MPa}$ and room temperature. They found that after six days of storage at $50 \mathrm{MPa}, E$. coli counts were reduced below the detection limit $(10 \mathrm{CFU} / \mathrm{mL})$. However, this pressure was not enough to avoid the growth of L. innocua and storage at $75 \mathrm{MPa}$ was needed to achieve the same results as in E. coli. These results confirm the greater sensitivity of Gram-negative bacteria (E. coli) to pressure when compared with Gram-positive bacteria (L. innocua), a well-known fact widely proven throughout the literature [32,34].

Furthermore, it is important to note that HS-RT can reduce not only the load of vegetative cells as conventional pasteurization does, but can also decrease the endospore load. Many papers in the literature have shown that relatively low pressures induce endospore germination [35-38]. Thus, during HS-RT, pressure can produce the germination of endospores, and at appropriate pressure levels, their subsequent outgrowth is not fulfilled. As previously discussed, the appropriate pressure level will depend on the characteristics of the juice and the specific microorganisms. In this sense, Pinto et al. [39] reported that storage at 25-100 MPa and room temperature unleashed the germination of B. subtilis endospores in previously inoculated carrot juices ( $\mathrm{pH}$ 6.0). After germination, B. subtilis cells grew at $25 \mathrm{MPa}$ and pressures of at least $50 \mathrm{MPa}$ were needed to avoid their proliferation. In contrast, in inoculated apple juice ( $\mathrm{pH} 3.5$ ), a storage pressure of $25 \mathrm{MPa}$ was enough to produce significant reductions in Alicyclobacillus acidoterrestris endospores that could not proliferate after germination [40]. In both juices, storage at 50-100 MPa reduced the total microbial load, and the larger the pressure, the quicker the microbial inactivation. For example, Pinto, Martins, Santos, Fidalgo, Delgadillo, and Saraiva [40] reported that Alicyclobacillus acidoterrestris spores inoculated in apple juice $\left(10^{4}-10^{5}\right.$ cells $\left./ \mathrm{mL}\right)$ were inactivated to an undetectable level $(<10 \mathrm{CFU} / \mathrm{mL})$ after 30 days at $50 \mathrm{MPa}$, but after only one day at $100 \mathrm{MPa}$.

\subsection{Enzymatic and Chemical Reactions}

It is well-known that pressure affects the rate of enzymatic and chemical reactions. Thus, those reactions with a negative partial activation volume will be enhanced under pressure, while those with a positive partial activation volume will be hindered [41]. Just after fruit juicing, the mixing of fruit enzymes with the substrate and air can rapidly initiate a number of enzymatic reactions that are capable of degrading nutrients and bioactive compounds, modifying pectin, and affecting color or flavor, among others. These enzymatic reactions, together with an endless number of chemical reactions involving oxygen, metal cations, and other juice constituents, can be extended during juice storage and produce significant quality losses [17]. Therefore, to assess the efficacy of hyperbaric storage in preserving fruit juices, it is essential to know which degradative reactions are pressure enhanced and which ones are inhibited.

The effect of pressure on a specific degradative reaction is usually assessed by comparing either the decrease in the reagents implied or the increase in the products formed after some time under different pressure levels. This is not a simple task because several enzymatic and non-enzymatic reactions can be simultaneously involved in the degradation of a specific compound and pressure can affect each of them in a different manner. To avoid the interference of undesired reagents and/or reactions, purified enzymes and food models are frequently used in kinetic studies. However, the results may not represent the real product as environmental factors such as $\mathrm{pH}$ and the presence of salts, sugar, or other food constituents can affect the reaction rates under pressure. In contrast, studies in real products frequently fail in identifying the effect of pressure on a specific reaction because many reactions can 
simultaneously occur, and therefore, only the net effects can be evaluated. Moreover, in this kind of study, microbial metabolism can be an additional factor that interferes with the results, and therefore, actions to prevent microbial growth should be taken.

During hyperbaric storage, enzymatic reactions can be accelerated or decelerated depending on the changes that pressure induces in the structure of the enzyme, the properties of the substrate and/or the solvent ( $\mathrm{pH}$, viscosity, density, and so on), or in the reaction mechanisms; for example, a change in the rate-limiting step [42]. Unfortunately, very scarce information exists about the catalytic activity of the enzymes responsible for fruit juice spoilage under pressure. Most studies have focused on pectin methylesterase (PME) or polygalacturonase (PG), two specific enzymes responsible for cloud destabilization and serum viscosity decay, but these are usually performed in model systems and at pressures significantly higher than those employed in HS-RT [43-46]. In general, these studies have shown that the catalytic activity under pressure not only depends on the specific enzyme and the pressure and temperature conditions applied, but also on the enzyme origin, the substrate employed, and the ionic environment.

Recently, Bermejo-Prada et al. [47] evaluated the catalytic activity of strawberry PME at pressure and temperature conditions similar to those employed in HS-RT. To do so, the authors compared the amount of methanol released during the enzymatic reaction at $0.1-200 \mathrm{MPa}$ and $20^{\circ} \mathrm{C}$. They reported that pressure up to $200 \mathrm{MPa}$ did not affect the catalytic activity of PME in the strawberry crude extract at $20^{\circ} \mathrm{C}$. Similar results were found by other authors in crude PME extracts from different plant sources such as tomato [45,48], carrot [44], or pepper [49] at pressures lower than $300 \mathrm{MPa}$. However, Bermejo-Prada, Segovia-Bravo, Guignon, and Otero [47] noted that unlike in the crude extract, pressure enhanced PME catalytic activity in strawberry juice. Thus, after two days of storage, pectin demethoxylation occurred significantly faster at $200 \mathrm{MPa}$ than at atmospheric pressure or at $50 \mathrm{MPa}$. To justify these results, the authors suggested that pressure could enhance the activity of some endogenous pectinases, other than PME, that reduced steric hindrances and eased the PME access to methyl ester bonds of pectin. For example, candidates could include pectin- and pectate-lyases as well as debranching enzymes that catalyze changes in pectin side chains such as galactosidases or arabinofuranosidases. In this connection, Bermejo-Prada [50] observed that, at room temperature, pressure up to $200 \mathrm{MPa}$ significantly reduced the catalytic activity of the crude strawberry $\beta$-galactosidase extract, and therefore, this enzyme could not be directly implicated in the enhanced pectine demethoxylation observed at $200 \mathrm{MPa}$. Studies on purified tomato PG also showed a reduced activity of this enzyme under pressure (100-400 MPa) at temperatures between $30^{\circ} \mathrm{C}$ and $50{ }^{\circ} \mathrm{C}[46,51]$. However, it is important to note that, as previously commented, results obtained in purified enzymes in buffer solutions may be not representative of real products, therefore more research about the activity of degradative enzymes under pressure is needed.

In real juices, there exists some rough information about the effect of hyperbaric storage on the rate of degradation of some bioactive compounds. To avoid microbial interferences, Bermejo-Prada and Otero [52] added an antimicrobial agent to strawberry juice and observed that HS-RT, either at $50 \mathrm{MPa}$ or at 200 MPa, for 1-14 days did not affect the degradation rate of total phenolics. In contrast, Pinto, Moreira, Fidalgo, Santos, Vidal, Delgadillo, and Saraiva [19] reported that the total phenolics in watermelon juice degraded more quickly at 50-100 MPa than at atmospheric pressure. Differences observed in strawberry and watermelon juices can be due to several reasons such as the composition of the food matrix, $\mathrm{pH}$, or the presence/absence of an antimicrobial agent. Moreover, different enzymatic and non-enzymatic mechanisms could be implied in the results. However, the usual total phenolics analysis in juices by the Folin-Ciocalteau method only gives rough estimations, and more specific methods should be employed to obtain detailed information about the degradation of specific compounds under pressure. In this sense, Bermejo-Prada and Otero [52] showed that HS-RT up to $200 \mathrm{MPa}$ did not affect the net degradation rate of total monomeric anthocyanins (TMA) in strawberry juice, although differences could exist in the mechanisms implied in TMA degradation at atmospheric and 
high pressure. Thus, significant peroxidase inactivation and lower polymerization were observed in the samples stored at $200 \mathrm{MPa}$ when compared with those maintained at atmospheric pressure.

The stability of carotenoids under pressure has been also explored. Pinto, Moreira, Fidalgo, Santos, Vidal, Delgadillo, and Saraiva [19] analyzed the evolution of lycopene content in watermelon juice during HS-RT and observed that after 10 days at $50 \mathrm{MPa}$ or $100 \mathrm{MPa}$, the lycopene content was similar to that in conventionally cold stored samples.

\section{Effect of Hyperbaric Storage on Juice Quality: Comparison with Conventional Cold Storage}

During juice storage, the action of the diverse degradative agents can produce changes in many physical and chemical attributes that finally result in undesirable quality losses in the product. As pressure can inhibit microbial growth, those changes associated with microorganisms can be efficiently avoided during HS-RT, but those associated with enzymatic and chemical reactions can be either enhanced or hampered, depending on the effects of pressure on their specific reaction rates. Furthermore, it is important to note that the rate of degradative reactions depends not only on pressure, but also on other factors such as temperature, $\mathrm{pH}$, the juice composition, or the procedure of juice production, among others, and therefore, general conclusions are not always easy to draw.

Hyperbaric storage at room temperature has been found to be more effective than conventional refrigeration in preserving some physicochemical attributes of fruit juices. Thus, Lemos, Ribeiro, Fidalgo, Delgadillo, and Saraiva [18] observed that the initial $\mathrm{pH}$ of watermelon juice was maintained for at least 21 days at $75 \mathrm{MPa}$ and room temperature, while it significantly decreased after seven days at atmospheric pressure and $4{ }^{\circ} \mathrm{C}$. HS-RT at 50-100 MPa was also effective in reducing the significant increase of the titratable acidity observed in watermelon juice after 7-10 days of conventional cold storage [19]. Data in the literature also show that HS-RT can preserve the aroma of fruit juices better than refrigeration. Thus, Bermejo-Prada et al. [53] observed that unlike conventional refrigeration, HS-RT at 50-200 MPa for 15 days did not produce changes in any key aroma compound of strawberry juice. However, other physicochemical attributes are better preserved during conventional cold storage as low temperature can be more effective than pressure in slowing down certain enzymatic and chemical reactions.

During juice storage, pigments can be degraded by both enzymatic and chemical reactions. Moreover, certain enzymes such as PPO, POD, or $\beta$-glucosidase are implied in the production of colored compounds that also modify the juice color. Data in the literature show that refrigeration preserves juice color better than HS-RT. For example, Segovia-Bravo, Guignon, Bermejo-Prada, Sanz, and Otero [9] noted lower color changes $(\Delta \mathrm{E})$ in strawberry juice conventionally cold stored at $5{ }^{\circ} \mathrm{C}$ for 15 days than in juices stored at 25-200 MPa and room temperature. Likewise, Lemos, Ribeiro, Fidalgo, Delgadillo, and Saraiva [18] noted that color changes in watermelon juices kept at $75 \mathrm{MPa}$ and room temperature for 21 days were significantly larger than those observed in juices stored either at $75 \mathrm{MPa}$ and $15^{\circ} \mathrm{C}$, or at atmospheric pressure and $4{ }^{\circ} \mathrm{C}$. However, it is important to note that even though the pressure level applied during HS-RT significantly affects the evolution of lightness, redness, yellowness, hue, or chroma in fruit juices [19,52], color changes during HS-RT are usually very slight. Thus, $\Delta \mathrm{E}$ values lower than 5 and 2 were detected in watermelon juice after 10 days at $75 \mathrm{MPa}[18,19]$ and $100 \mathrm{MPa}[19]$, respectively, while, in strawberry juice, $\Delta \mathrm{E}$ values lower than 1.5 were observed after 15 days at 25-220 MPa [9,52]. Although color differences larger than 2-4 are considered perceptible to the naked eye, $\Delta \mathrm{E}<5$ are small in practical terms.

The appearance of a juice is not only affected by the stability of pigments or the formation of colored substances during storage, but also by the juice turbidity or cloudiness. During storage, microbial proliferation can increase juice turbidity, while the decantation of solid particles in suspension decreases juice cloudiness. This decantation is mainly produced by viscosity losses in the juice serum. Serum viscosity affects not only the ability to hold the solid particles of the juice in suspension, but also the mouthfeel. During storage, viscosity usually decreases and this decay is generally attributed to the depolymerization of pectin caused, as previously commented, by the combined action of different 
endogenous pectinases together with microbial growth that also implies an associated enzymatic activity. Pinto, Moreira, Fidalgo, Santos, Vidal, Delgadillo, and Saraiva [19] and Pinto, Moreira, Fidalgo, Santos, Delgadillo, and Saraiva [20] showed that during storage at atmospheric pressure and room temperature, the cloudiness of watermelon juice increased, probably due to microbial proliferation, and refrigeration was an efficient method to slow down this increase significantly. In contrast, HS-RT at $100 \mathrm{MPa}$ produced a significant decrease in the cloudiness of watermelon juice, most likely due to the pressure-enhanced activity of pectinases that reduced serum viscosity. In this sense, Bermejo-Prada, Segovia-Bravo, Guignon, and Otero [47] observed that at room temperature, the serum viscosity of strawberry juices reduced very quickly and the larger the storage pressure, the greater the viscosity decay. Thus, after only one day of storage, they detected viscosity drops of $42.5 \%, 55.5 \%$, and $74.5 \%$ in strawberry juices kept at $0.1,50$, and $220 \mathrm{MPa}$, respectively. These viscosity drops are likely to be responsible for cloudiness losses that can be related, in turn, with certain color changes during storage.

\section{Juice Stability after Hyperbaric Storage}

After hyperbaric storage, fruit juices may not always be immediately consumed or processed, but stored for some time at atmospheric pressure. In these cases, it is important to assess the activity of the surviving microorganisms by comparing microbial loads just after hyperbaric storage and after a certain recovery period at atmospheric pressure as well as the residual activity of the main enzymes implied in fruit juice spoilage.

Even though there is much information about the behavior of the main degradative agents and the quality evolution in fruit juices after pressure treatments, most studies are performed at the conditions usually employed in conventional high-pressure processing [54-56] that, as previously commented, are quite different to those applied in hyperbaric storage. Specific studies about the fruit juice stability after HS-RT are very scarce and the results obtained are commented on in the following paragraphs.

It is well-known that under relatively low pressures such as those usually employed in HS-RT, microorganisms are more likely to be stressed or injured, than killed. Thus, once high pressure is released, cells can repair the injuries and proliferate [21,57]. Data in the literature show that microbial recovery after HS-RT depends on the same factors that affect microbial growth during HS-RT. Thus, the storage pressure plays a significant role and the larger the pressure during HS-RT, the more difficult the microbial recovery is when the product returns to atmospheric conditions. For example, Bermejo-Prada, López-Caballero, and Otero [25] observed that after one day of storage at 25-50 MPa, surviving TAM, LAB, and YM in strawberry juice recovered their cell-proliferating capacity and were able to grow when the juice was maintained at atmospheric pressure and room temperature for three days. In contrast, after one day of storage at $200 \mathrm{MPa}$, the microorganisms were seriously damaged and counts after three recovery days at atmospheric pressure were under the detection limits (1 CFU/mL for TAM and LAB, and $10 \mathrm{CFU} / \mathrm{mL}$ for $\mathrm{YM}$ ). Moreover, longer storage times make microbial recovery more difficult than shorter ones. Thus, microorganisms in strawberry juices kept at $50 \mathrm{MPa}$ for 1-10 days recovered their cell-proliferating ability after decompression much better than those in juices maintained 15 days at the same pressure level. The product characteristics are also very important for the juice stability after hyperbaric storage. For example, after one day at $100 \mathrm{MPa}$, surviving TAM, $\mathrm{LAB}$, and $\mathrm{YM}$ in strawberry juice hardly grew when the juice was kept at atmospheric pressure and room temperature for three days [25]. In contrast, surviving TAM, LAB, and YM in watermelon juice kept at $100 \mathrm{MPa}$ for 2.5 days were able to grow after pressure release when the juice was stored at atmospheric pressure and $5{ }^{\circ} \mathrm{C}$ for 7-14 days [26]. The bacteriostatic effect observed in strawberry juice seems to be due to the low $\mathrm{pH}$ of the product as surviving TAM, LAB, and YM were able to form colonies when they were plated on the appropriate media immediately after hyperbaric storage. Thus, low $\mathrm{pH}$ in juices could not only enhance microbial damage during pressure storage, but also inhibit the outgrowth of sub-lethally injured cells after decompression. All of the above results clearly show that microorganisms can recover their cell-proliferating capacity after hyperbaric storage, especially after 
short times at relatively low pressure. Therefore, fruit juices should be appropriately preserved after HS-RT if they are not going to be immediately consumed or processed.

Regarding other degradation agents apart from microorganisms, some data exist on a few enzymes responsible for juice decay. As observed for microorganisms, the residual activity after hyperbaric storage seems to depend not only on the specific enzyme, the pressure applied, or the storage time, but also on the product characteristics.

In general, PME activity significantly decreases during storage, either at atmospheric or at higher pressure, and the longer the storage, the lower the residual PME activity. Thus, Bermejo-Prada, Segovia-Bravo, Guignon, and Otero [47] stored strawberry juice (with an added antibiotic agent) at different pressure levels $(0.1,50$, and $200 \mathrm{MPa})$ for $1-15$ days and observed that PME activity decreased more slowly at $200 \mathrm{MPa}$ than at atmospheric pressure or at $50 \mathrm{MPa}$. The authors attributed this effect to an apparent activation of the enzyme at $200 \mathrm{MPa}$ caused by the pressure-enhanced PME release from small cell wall particles present in the juice. However, after seven days of storage, PME activity was similar in all of the juices stored at different pressures, and after 15 days of storage, the residual PME activities were $56 \%, 52 \%$, and $57 \%$ in juices kept at $0.1,50$, and $200 \mathrm{MPa}$, respectively. In contrast, Pinto, Moreira, Fidalgo, Santos, Vidal, Delgadillo, and Saraiva [19] observed that in watermelon juice, the higher the storage pressure, the lower the residual PME activity, and after 10 days of storage, they measured residual PME activities of $53.5 \%$ and $42.8 \%$ in samples stored at $50 \mathrm{MPa}$ and $100 \mathrm{MPa}$, respectively. These slight differences observed in strawberry and watermelon juices could be due to different factors such as the product characteristics (composition, $\mathrm{pH}$, cell wall particles in the juice, and so on) or the effect of the presence/absence of an antimicrobial agent during storage.

A few data also exist on the residual activity, after HS-RT, of some enzymes responsible for color, aroma, or taste degradation. As observed for PME, the residual activity of peroxidase (POD) decreased after hyperbaric storage. Thus, after 10 days of storage, POD activity reduced to $16.8 \%$ in watermelon juices kept at $100 \mathrm{MPa}$ [19], while it was $85 \%$ in strawberry juices stored at $200 \mathrm{MPa}$ for 15 days [52]. Polyphenoloxidase (PPO) seems to be less pressure labile than POD. Thus, in strawberry juice, PPO activity increased during storage regardless of the storage pressure, and residual PPO activities of $141 \%, 159 \%$, and $152 \%$ were detected after 15 days at atmospheric pressure, $50 \mathrm{MPa}$, and $200 \mathrm{MPa}$, respectively. In contrast, in watermelon juice, PPO activity significantly decreased during storage, but the higher the storage pressure, the larger the residual PPO activity. Thus, after seven days at atmospheric pressure, the residual PPO activity was $9.5 \%$, while it was larger than $50 \%$ in the samples stored at 50-100 MPa.

There is very scarce information about the evolution of the quality attributes of fruit juices after hyperbaric storage. Few existing data show that storage under pressure does not accelerate quality losses after expansion if appropriate preservation techniques are subsequently applied. For example, Segovia-Bravo, Guignon, Bermejo-Prada, Sanz, and Otero [9] observed that after 15 days of storage at 25-220 MPa, the color of strawberry juices remained stable for at least 15 days at atmospheric pressure and $5{ }^{\circ} \mathrm{C}$ where only a very slight viscosity decay was detected.

\section{Consumer Acceptability}

Even though the instrumental measurements described in the previous sections provide encouraging evidences of the efficacy of HS-RT in preserving fruit juice quality, it is important to evaluate the consumer perception as instrumental measurements and sensorial analysis are frequently not well correlated.

Hedonic sensory analysis has shown that HS-RT for 15 days at either 100 or 220 MPa did not produce any perceptible change in color, odor, taste, or the overall acceptance of strawberry juice [50]. In contrast, after 15 days at $25 \mathrm{MPa}$, the hedonic scores of taste and overall acceptance significantly decreased although those of color and odor remained unaltered. This is in agreement with the low color differences $(\Delta \mathrm{E}=1.3)$ and the volatile profiles instrumentally measured in these juices. In this sense, after an informal smell evaluation, Lemos, Ribeiro, Fidalgo, Delgadillo, and Saraiva [18] also 
reported that watermelon juice stored either at $62.5 \mathrm{MPa}$ for 58 days or at $75 \mathrm{MPa}$ for 21 days presented a fresh-like smell, with no sign of off-flavors.

Triangle tests have confirmed that hyperbaric storage at pressures lower than $50 \mathrm{MPa}$ is not able to maintain all of the original organoleptic properties of strawberry juice, therefore, juices stored for 15 days at 25-50 MPa were perceived as different from the juice before storage [58]. Taste changes during hyperbaric storage at $25 \mathrm{MPa}$ were verified, and even though instrumental titratable acidity, $\mathrm{pH}$, and total soluble solids measurements did not change during HS-RT, some judges described the taste of the juices kept at $25 \mathrm{MPa}$ as more sour than that of the juice at day 0 [50]. In contrast, juices stored at $50 \mathrm{MPa}$ were perceived as different more because of their lower viscosity than because of their sour flavor. This was in agreement with the large decrease $(\approx 93 \%)$ observed in the instrumental viscosity measurements. When asked about their preferences, most judges preferred the fresh strawberry juice at day 0 than those kept at $25-50 \mathrm{MPa}$ for 15 days.

Cold storage after pasteurization, that is, the conventional storage strategy, was not effective in preserving the original organoleptic properties of strawberry juices either. Surprisingly, after 15 days of storage, the pasteurized juices were preferred to the raw juices at day 0 probably because they were described as sweeter. This sweet flavor could be caused by the caramelization of the sugars contained in the juice during thermal processing. To avoid the influence of caramelization when comparing the consumer preference between conventional cold storage and HS-RT, Bermejo-Prada, Colmant, Otero, and Guignon [58] stored pasteurized strawberry juices either at atmospheric pressure and $5{ }^{\circ} \mathrm{C}$ or at $25 \mathrm{MPa}$ and $20^{\circ} \mathrm{C}$ for 15 days. Triangle tests in these pasteurized juices revealed that the judges could not notice any sensory difference between them. Therefore, HS-RT at $25 \mathrm{MPa}$ and conventional cold storage preserved their organoleptic properties with the same efficacy.

\section{Industrial Implementation}

As previously mentioned, many papers in the literature have confirmed the efficacy of HS-RT to extend, in terms of food safety and quality, the shelf-life of not only fruit juices, but also a wide variety of food products. Despite this, HS-RT has not yet been introduced in the industry, probably due to the lack of equipment specially designed for it.

Figure 1 presents a simplified description of how hyperbaric storage could be implemented in a juice factory. Once the juice has been obtained, it would be pumped in tanks and pressurized. Then, the pressurized tanks would be sealed with a valve to avoid pressure release and moved to a warehouse. Here, the pressurized juice would be stored at room temperature until distribution. Depending on the customer demands, distribution could be performed either under pressure or the tanks could be decompressed prior to transport.

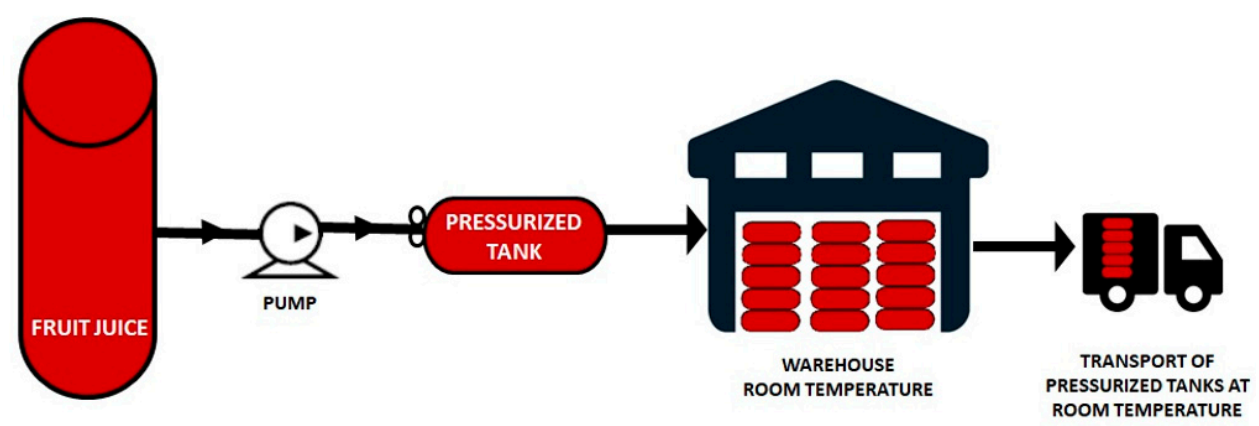

Figure 1. Ideal implementation of hyperbaric storage in a fruit juice factory.

It is clear from Figure 1 that the main components needed in a HS-RT installation are simple: a hydraulic pump and a set of pressure tanks. As pressures employed in HS-RT are quite moderate, the hydraulic pump should not be a problem, but the pressure tanks could present one as currently, tanks do not exist that have been specifically designed for food storage under pressure. Obviously, 
the feasibility of the logistics management at an industrial scale will depend on the size and weight of these tanks. They must be moved from the pressurization point to the warehouse and then transported to their final destination. Too large or too heavy tanks would make these displacements unviable.

The tank size and weight depend on several factors such as the tank material, the tank shape, the amount of product to store, and the storage pressure (the higher the storage pressure, the thicker the tank wall). Taking into account that typical forklifts can easily move loads up to $3000 \mathrm{~kg}$, Bermejo-Prada, Colmant, Otero, and Guignon [58] deemed pressure tanks larger than $2 \mathrm{~m}$ and heavier than $2000 \mathrm{~kg}$ (mass of the vessel filled with product) would be difficult to handle inside an industrial facility. They considered cylindrical stainless steel (15-5 PH) tanks, with a fixed diameter/length ratio (0.66), and calculated a domain of viable designs for variable product masses and storage pressures. For a storage pressure of $25 \mathrm{MPa}$, the largest viable tank should have a length of $1.6 \mathrm{~m}$, a diameter of $1.1 \mathrm{~m}$, and could store $1040 \mathrm{~kg}$ of strawberry juice. This volume is much larger than the standard juice batches sold in the industry that usually do not exceed $200 \mathrm{~kg}$. For this mass of juice, the maximal storage pressure for which the tank design would be viable would be $157 \mathrm{MPa}$. This pressure level is considerably larger than those needed for fruit juice preservation, which are usually between 50 and $100 \mathrm{MPa}$. Therefore, the construction and handling of pressure tanks appropriate for hyperbaric storage is perfectly viable.

However, logistics management is not the only consideration needed to assess the feasibility of its industrial implementation. The cost of hyperbaric storage is also an important factor to take into account. When calculating the storage cost, the amortization cost of the initial investment, the maintenance cost, and the electricity consumption throughout the storage period must be considered. Taking all of these factors into account, Bermejo-Prada, Colmant, Otero, and Guignon [58] estimated that, today, the HS-RT cost would be considerably higher than that of conventional refrigeration. Even though the electrical consumption in HS-RT is almost negligible, the initial cost of the HS-RT equipment is high and this is, without any doubt, the limiting factor for the implementation of this technology in the food industry. However, it is important to note that the high price of high-pressure equipment has not been an impediment for the successful industrial implantation of conventional high-pressure processing, and thanks to the increasing demand, a decreasing trend in the cost of high-pressure equipment has been observed from 1996 to now. In contrast, the growing tendency of electricity prices could increase the refrigeration cost in the following years and contribute to making this technology less competitive from an economic point of view.

\section{Environmental Impact of Hyperbaric Storage}

The environmental impact of hyperbaric storage can be roughly estimated by calculating its carbon footprint $(\mathrm{CF})$, that is, the overall emissions of carbon dioxide $\left(\mathrm{CO}_{2}\right)$ and other greenhouse gases associated with it. To do so, the equivalent $\mathrm{CO}_{2}$ emissions associated with both the production of the high-pressure vessel material (direct emissions) and the energy consumption during operation (indirect emissions) must be considered. In this way, Bermejo-Prada, Colmant, Otero, and Guignon [58] estimated that the total $\mathrm{CF}$ associated with the storage of $1 \mathrm{~kg}$ of strawberry juice at $25 \mathrm{MPa}$ for 15 days was $0.0042 \mathrm{~kg} \mathrm{CO} \cdot \mathrm{kg}^{-1}$ juice. They showed that the HS-RT emissions associated with the vessel material corresponded to almost $100 \%$ of the emissions while those derived from the electricity consumption during storage were almost negligible (Figure 2). In contrast, in conventional refrigeration, the total CF was $0.1085 \mathrm{~kg} \mathrm{CO}_{2} \cdot \mathrm{kg}^{-1}$ juice, that is, 26 times higher than that of HS-RT and the consumed electricity and refrigerant leakage amounted to almost $95 \%$ of the $\mathrm{CO}_{2}$ total emissions.

Cold facilities are huge consumers of energy and represent about $50 \%$ of the total energy consumption in the food industry [5]. Moreover, refrigerants are an important source of GHG emissions and some of them also split and release ozone destructive chlorine atoms. Therefore, HS-RT could represent an important breakthrough for food preservation in terms of refrigerant elimination, energy saving, and environmental protection. Thus, the above results prove that both the needlessness of refrigeration facilities and the extremely low energy requirements (only during 
compression of the product) represent a real environmental benefit as they contribute to greatly diminish the HS-RT carbon footprint. This is especially important today when global energy savings are demanded in the food industry to fight against climate change.

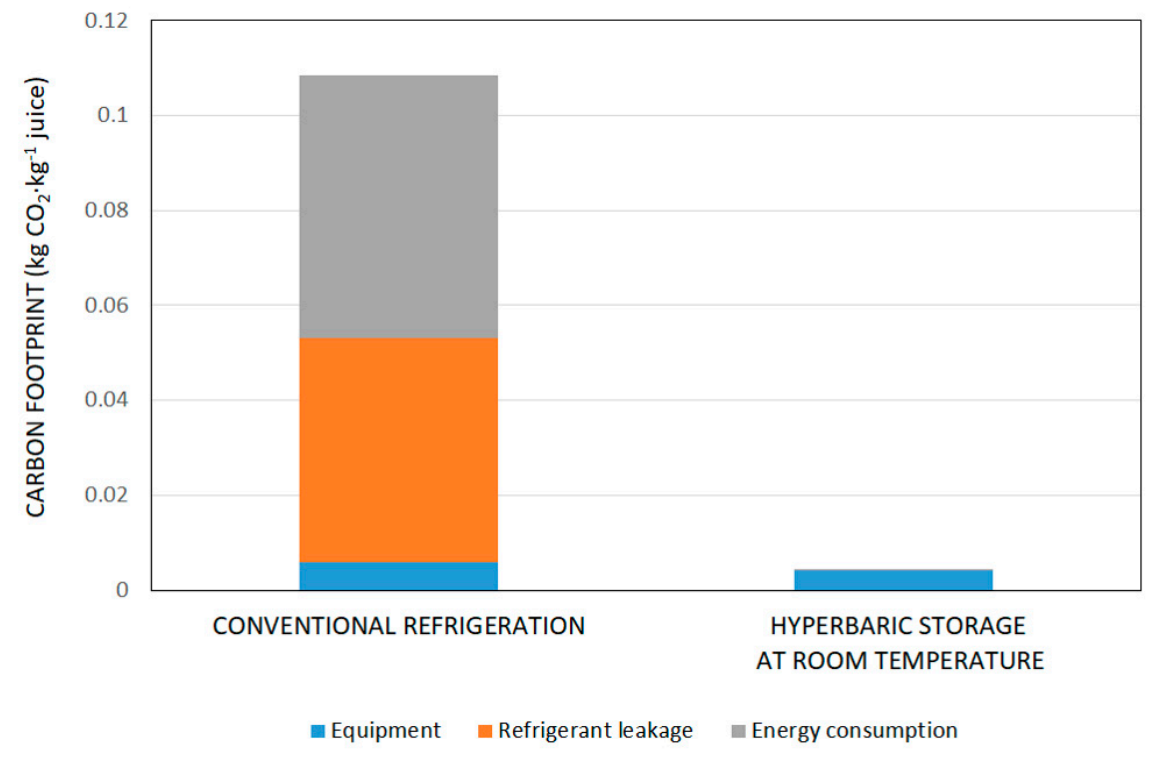

Figure 2. Contribution of different sources to $\mathrm{CO}_{2}$ emissions in conventional refrigeration and hyperbaric storage at room temperature.

\section{Conclusions}

In this paper, HS-RT has been presented as an efficient method to preserve fruit juices in terms of juice safety and quality, consumer acceptability, industrial implementation, and environmental impact. Its main advantage over other conventional preservation methods is its extremely low energy consumption. HS-RT could be employed in a wide variety of scenarios: the food industry, ship or truck transport for long distances, school or hospital kitchens, restaurants, or even at home. Moreover, its application in developing countries, where the continuous supply of electric energy is difficult, would be especially noteworthy.

Even though the existing literature analyzed in this paper provides evidence of the feasibility of this method for fruit juice preservation, much more research is still needed. First, HS-RT should be tested on a wide variety of juices obtained from different fruits (e.g., acidic and low-acidic juices, clarified or not, obtained from only one fruit or by mixing a combination of fruit juices and purees) to assess the effect that fruit juice composition can have on quality decay under pressure.

Second, the effect of pressure on the main mechanisms implied in the spoilage of fruit juices should be evaluated in depth. Most existing studies have focused on microorganisms as the main agents responsible for juice spoilage, but the effect of pressure on other degradation agents such as enzymatic and chemical reactions should not be forgotten. In this sense, specific studies to analyze the degradation of relevant compounds (specific vitamins, bioactive compounds, pigments, and so on) under pressure should be designed.

Third, research effort should be particularly focused in identifying issues that could pose a problem for the success of HS-RT such as the adaptation of microbial strains to pressure stress or the pressure-enhanced formation of undesired compounds during storage, among others.

Finally, equipment development for the practical application of HS-RT remains a challenge. Even though pressure tanks do not involve a technological challenge today, their price could be an important limitation. The development of new materials that are able to resist high pressures but are cheaper than steel could help in the industrial success of HS-RT. 
Funding: This research received no external funding.

Conflicts of Interest: The author declares no conflict of interest.

\section{References}

1. IMARC Group. Fruit Juice Market: Global Industry Trends, Share, Size, Growth, Opportunity and Forecast 2019-2024. Available online: https://www.imarcgroup.com/fruit-juice-manufacturing-plant (accessed on 20 May 2019).

2. AIJN. European Fruit Juice Association. 2018 Liquid Fruit Market Report. Available online: http://viewer. zmags.com/publication/bc62cfea\#/bc62cfea/1 (accessed on 20 May 2019).

3. Vermeulen, S.J.; Campbell, B.M.; Ingram, J.S.I. Climate change and food systems. Annu. Rev. Environ. Resour. 2012, 37, 195-222. [CrossRef]

4. Pelletier, N.; Audsley, E.; Brodt, S.; Garnett, T.; Henriksson, P.; Kendall, A.; Kramer, K.J.; Murphy, D.; Nemecek, T.; Troell, M. Energy intensity of agriculture and food Systems. Annu. Rev. Environ. Resour. 2011, 36, 223-246. [CrossRef]

5. James, S.J.; James, C. The food cold-chain and climate change. Food Res. Int. 2010, 43, 1944-1956. [CrossRef]

6. Charm, S.E.; Longmaid, H.E.; Carver, J. Simple system for extending refrigerated, nonfrozen preservation of biological-material using pressure. Cryobiology 1977, 14, 625-636. [CrossRef]

7. Hirsch, G.P. Method of Pressure Preservation of Food Products. U.S. Patent 5,593,714, 14 January 1997.

8. Hirsch, G.P. Hydraulic Pressure Sterilization and Preservation of Foodstuff and Feedstuff. U.S. Patent 6,033,701, 7 March 2000.

9. Segovia-Bravo, K.A.; Guignon, B.; Bermejo-Prada, A.; Sanz, P.D.; Otero, L. Hyperbaric storage at room temperature for food preservation: A study in strawberry juice. Innov. Food Sci. Emerg. Technol. 2012, 15, 14-22. [CrossRef]

10. Freitas, P.; Pereira, S.A.; Santos, M.D.; Alves, S.P.; Bessa, R.J.B.; Delgadillo, I.; Saraiva, J.A. Performance of raw bovine meat preservation by hyperbaric storage (quasi energetically costless) compared to refrigeration. Meat Sci. 2016, 121, 64-72. [CrossRef] [PubMed]

11. Fernandes, P.A.; Moreira, S.A.; Santos, M.D.; Duarte, R.V.; Santos, D.I.; Inacio, R.S.; Alves, S.P.; Bessa, R.J.; Delgadillo, I.; Saraiva, J.A. Hyperbaric storage at variable room temperature-a new preservation methodology for minced meat compared to refrigeration. J. Sci. Food Agric. 2019, 99, 3276-3282. [CrossRef]

12. Fernandes, P.A.R.; Moreira, S.A.; Duarte, R.; Santos, D.I.; Queirós, R.P.; Fidalgo, L.G.; Santos, M.D.; Delgadillo, I.; Saraiva, J.A. Preservation of sliced cooked ham at 25,30 and $37{ }^{\circ} \mathrm{C}$ under moderated pressure (hyperbaric storage) and comparison with refrigerated storage. Food Bioprod. Process. 2015, 95, $200-207$. [CrossRef]

13. Duarte, R.V.; Moreira, S.A.; Fernandes, P.A.R.; Fidalgo, L.G.; Santos, M.D.; Queirós, R.P.; Santos, D.I.; Delgadillo, I.; Saraiva, J.A. Preservation under pressure (hyperbaric storage) at $25^{\circ} \mathrm{C}, 30^{\circ} \mathrm{C}$ and $37^{\circ} \mathrm{C}$ of a highly perishable dairy food and comparison with refrigeration. CyTA J. Food 2015, 13, 321-328. [CrossRef]

14. Duarte, R.V.; Moreira, S.A.; Fernandes, P.A.R.; Santos, D.I.; Inácio, R.S.; Alves, S.P.; Bessa, R.J.B.; Saraiva, J.A. Whey cheese longer shelf-life achievement at variable uncontrolled room temperature and comparison to refrigeration. J. Food Process. Preserv. 2017, 41, e13307. [CrossRef]

15. Moreira, S.A.; Fernandes, P.A.; Duarte, R.; Santos, D.I.; Fidalgo, L.G.; Santos, M.D.; Queiros, R.P.; Delgadillo, I.; Saraiva, J.A. A first study comparing preservation of a ready-to-eat soup under pressure (hyperbaric storage) at $25{ }^{\circ} \mathrm{C}$ and $30^{\circ} \mathrm{C}$ with refrigeration. Food Sci. Nutr. 2015, 3, 467-474. [CrossRef] [PubMed]

16. Moreira, S.A.; Duarte, R.V.; Fernandes, P.A.R.; Alves, S.P.; Bessa, R.J.; Delgadillo, I.; Saraiva, J.A. Hyperbaric storage preservation at room temperature using an industrial-scale equipment: Case of two commercial ready-to-eat pre-cooked foods. Innov. Food Sci. Emerg. Technol. 2015, 32, 29-36. [CrossRef]

17. Bates, R.P.; Morris, J.R.; Crandall, P.G. Principles and Practices of Small-and Medium-Scale Fruit Juice Processing; FAO Agricultural Services Bulletin; Food and Agriculture Organization of the United Nations: Rome, Italy, 2001; Volume 146.

18. Lemos, Á.T.; Ribeiro, A.C.; Fidalgo, L.G.; Delgadillo, I.; Saraiva, J.A. Extension of raw watermelon juice shelf-life up to 58 days by hyperbaric storage. Food Chem. 2017, 231, 61-69. [CrossRef] [PubMed] 
19. Pinto, C.; Moreira, S.A.; Fidalgo, L.G.; Santos, M.D.; Vidal, M.; Delgadillo, I.; Saraiva, J.A. Impact of different hyperbaric storage conditions on microbial, physicochemical and enzymatic parameters of watermelon juice. Food Res. Int. 2017, 99, 123-132. [CrossRef] [PubMed]

20. Pinto, C.; Moreira, S.A.; Fidalgo, L.G.; Santos, M.D.; Delgadillo, I.; Saraiva, J.A. Shelf-life extension of watermelon juice preserved by hyperbaric storage at room temperature compared to refrigeration. LWT Food Sci. Technol. 2016, 72, 78-80. [CrossRef]

21. Abe, F. Exploration of the effects of high hydrostatic pressure on microbial growth, physiology and survival: Perspectives from piezophysiology. Biosci. Biotechnol. Biochem. 2007, 71, 2347-2357. [CrossRef]

22. Bartlett, D.H. Pressure effects on in vivo microbial processes. Biochim. Biophys. Acta Protein Struct. Mol. Enzymol. 2002, 1595, 367-381. [CrossRef]

23. Mota, M.J.; Lopes, R.P.; Delgadillo, I.; Saraiva, J.A. Microorganisms under high pressure-Adaptation, growth and biotechnological potential. Biotechnol. Adv. 2013, 31, 1426-1434. [CrossRef]

24. Aoyama, Y.; Shigeta, Y.; Okazaki, T.; Hagura, Y.; Suzuki, K. Growth inhibition of microorganisms by hydrostatic pressure. Food Sci. Technol. Res. 2004, 10, 268-272. [CrossRef]

25. Bermejo-Prada, A.; López-Caballero, M.E.; Otero, L. Hyperbaric storage at room temperature: Effect of pressure level and storage time on the natural microbiota of strawberry juice. Innov. Food Sci. Emerg. Technol. 2016, 33, 154-161. [CrossRef]

26. Fidalgo, L.; Santos, M.; Queirós, R.; Inácio, R.; Mota, M.; Lopes, R.; Gonçalves, M.; Neto, R.; Saraiva, J. Hyperbaric storage at and above room temperature of a highly perishable food. Food Bioprocess Technol. 2014, 7, 2028-2037. [CrossRef]

27. Lado, B.H.; Yousef, A.E. Alternative food-preservation technologies: Efficacy and mechanisms. Microbes Infect. 2002, 4, 433-440. [CrossRef]

28. Queirós, R.P.; Santos, M.D.; Fidalgo, L.G.; Mota, M.J.; Lopes, R.P.; Inácio, R.S.; Delgadillo, I.; Saraiva, J.A. Hyperbaric storage of melon juice at and above room temperature and comparison with storage at atmospheric pressure and refrigeration. Food Chem. 2014, 147, 209-214. [CrossRef]

29. Santos, M.D.; Queirós, R.P.; Fidalgo, L.G.; Inácio, R.S.; Lopes, R.P.; Mota, M.J.; Sousa, S.G.; Delgadillo, I.; Saraiva, J.A. Preservation of a highly perishable food, watermelon juice, at and above room temperature under mild pressure (hyperbaric storage) as an alternative to refrigeration. LWT Food Sci. Technol. 2015, 62, 901-905. [CrossRef]

30. Matsumura, P.; Keller, D.; Marquis, R. Restricted $\mathrm{pH}$ ranges and reduced yields for bacterial growth under pressure. Microb. Ecol. 1974, 1, 176-189. [CrossRef]

31. Crelier, S.; Robert, M.C.; Claude, J.; Juillerat, M.A. Tomato (Lycopersicon esculentum) pectin methylesterase and polygalacturonase behaviors regarding heat- and pressure-induced inactivation. J. Agric. Food. Chem. 2001, 49, 5566-5575. [CrossRef]

32. Farkas, D.F.; Hoover, D.G. High pressure processing. J. Food Sci. 2000, 65, 47-64. [CrossRef]

33. Linton, M.; McClements, J.M.J.; Patterson, M.F. Inactivation of Escherichia coli O157:H7 in orange juice using a combination of high pressure and mild heat. J. Food Prot. 1999, 62, 277-279. [CrossRef]

34. Patterson, M.F. Microbiology of pressure-treated foods. J. Appl. Microbiol. 2005, 98, 1400-1409. [CrossRef]

35. Sarker, M.R.; Akhtar, S.; Torres, J.A.; Paredes-Sabja, D. High hydrostatic pressure-induced inactivation of bacterial spores. Crit. Rev. Microbiol. 2015, 41, 18-26. [CrossRef]

36. Wuytack, E.Y.; Michiels, C.W. A study on the effects of high pressure and heat on Bacillus subtilis spores at low pH. Int. J. Food Microbiol. 2001, 64, 333-341. [CrossRef]

37. Wuytack, E.Y.; Soons, J.; Poschet, F.; Michiels, C.W. Comparative study of pressure- and nutrient-induced germination of Bacillus subtilis spores. Appl. Environ. Microbiol. 2000, 66, 257-261. [CrossRef]

38. Borch-Pedersen, K.; Mellegård, H.; Reineke, K.; Boysen, P.; Sevenich, R.; Lindbäck, T.; Aspholm, M. Effects of high pressure on Bacillus licheniformis germination and inactivation. Appl. Environ. Microbiol. 2017, 83, e00503-e00517. [CrossRef]

39. Pinto, C.A.; Santos, M.D.; Fidalgo, L.G.; Delgadillo, I.; Saraiva, J.A. Enhanced control of Bacillus subtilis endospores development by hyperbaric storage at variable/uncontrolled room temperature compared to refrigeration. Food Microbiol. 2018, 74, 125-131. [CrossRef]

40. Pinto, C.A.; Martins, A.P.; Santos, M.D.; Fidalgo, L.G.; Delgadillo, I.; Saraiva, J.A. Growth inhibition and inactivation of Alicyclobacillus acidoterrestris endospores in apple juice by hyperbaric storage at ambient temperature. Innov. Food Sci. Emerg. Technol. 2019, 52, 232-236. [CrossRef] 
41. Torres, J.A.; Sanz, P.D.; Otero, L.; Pérez Lamela, M.C.; Aranda Saldaña, M.D. Temperature distribution and chemical reactions in foods treated by pressure-assisted thermal processing. In Processing Effects on Safety and Quality of Foods; CRC Press: Boca Raton, FL, USA, 2009; pp. 415-440.

42. Eisenmenger, M.J.; Reyes de Corcuera, J.I. High pressure enhancement of enzymes: A review. Enzyme Microb. Technol. 2009, 45, 331-347. [CrossRef]

43. Duvetter, T.; Fraeye, I.; Sila, D.N.; Verlent, I.; Smout, C.; Clynen, E.; Schoofs, L.; Schols, H.; Hendrickx, M.; Van Loey, A. Effect of temperature and high pressure on the activity and mode of action of fungal pectin methyl esterase. Biotechnol. Prog. 2006, 22, 1313-1320. [CrossRef]

44. Sila, D.N.; Smout, C.; Satara, Y.; Truong, V.; Van Loey, A.; Hendrickx, M. Combined thermal and high pressure effect on carrot pectinmethylesterase stability and catalytic activity. J. Food Eng. 2007, 78, 755-764. [CrossRef]

45. Van Den Broeck, I.; Ludikhuyze, L.R.; Van Loey, A.M.; Hendrickx, M.E. Effect of temperature and/or pressure on tomato pectinesterase activity. J. Agric. Food Chem. 2000, 48, 551-558. [CrossRef]

46. Verlent, I.; Van Loey, A.; Smout, C.; Duvetter, T.; Hendrickx, M.E. Purified tomato polygalacturonase activity during thermal and high-pressure treatment. Biotechnol. Bioeng. 2004, 86, 63-71. [CrossRef]

47. Bermejo-Prada, A.; Segovia-Bravo, K.A.; Guignon, B.; Otero, L. Effect of hyperbaric storage at room temperature on pectin methylesterase activity and serum viscosity of strawberry juice. Innov. Food Sci. Emerg. Technol. 2015, 30, 170-176. [CrossRef]

48. Verlent, I.; Loey, A.V.; Smout, C.; Duvetter, T.; Nguyen, B.L.; Hendrickx, M.E. Changes in purified tomato pectinmethylesterase activity during thermal and high pressure treatment. J. Sci. Food Agric. 2004, 84, 1839-1847. [CrossRef]

49. Castro, S.M.; Loey, A.V.; Saraiva, J.A.; Smout, C.; Hendrickx, M. Identification of pressure/temperature combinations for optimal pepper (Capsicum annuum) pectin methylesterase activity. Enzyme Microb. Technol. 2006, 38, 831-838. [CrossRef]

50. Bermejo-Prada, A. Hyperbric Storage of Foods at Room Temperature: Characterization in Strawberry Juice. Ph.D. Thesis, Complutense University of Madrid, Madrid, Spain, 2015.

51. Verlent, I.; Smout, C.; Duvetter, T.; Hendrickx, M.E.; Van Loey, A. Effect of temperature and pressure on the activity of purified tomato polygalacturonase in the presence of pectins with different patterns of methyl esterification. Innov. Food Sci. Emerg. Technol. 2005, 6, 293-303. [CrossRef]

52. Bermejo-Prada, A.; Otero, L. Effect of hyperbaric storage at room temperature on color degradation of strawberry juice. J. Food Eng. 2016, 169, 141-148. [CrossRef]

53. Bermejo-Prada, A.; Vega, E.; Pérez-Mateos, M.; Otero, L. Effect of hyperbaric storage at room temperature on the volatile profile of strawberry juice. LWT Food Sci. Technol. 2015, 62, 906-914. [CrossRef]

54. Gupta, R.; Balasubramaniam, V.M. High-pressure processing of fluid foods. In Novel Thermal and Non-Thermal Technologies for Fluid Foods; Cullen, P.J., Brijesh, K.T., Valdramidis, V.P., Eds.; Academic Press: San Diego, CA, USA, 2012; pp. 109-133.

55. Koutchma, T.; Popović, V.; Ros-Polski, V.; Popielarz, A. Effects of ultraviolet light and high-pressure processing on quality and health-related constituents of fresh juice products. Compr. Rev. Food Sci. Food Saf. 2016, 15, 844-867. [CrossRef]

56. Chakraborty, S.; Kaushik, N.; Rao, P.S.; Mishra, H.N. High-pressure inactivation of enzymes: A review on its recent applications on fruit purees and juices. Compr. Rev. Food Sci. Food Saf. 2014, 13, 578-596. [CrossRef]

57. Huang, H.-W.; Lung, H.-M.; Yang, B.B.; Wang, C.-Y. Responses of microorganisms to high hydrostatic pressure processing. Food Control 2014, 40, 250-259. [CrossRef]

58. Bermejo-Prada, A.; Colmant, A.; Otero, L.; Guignon, B. Industrial viability of the hyperbaric method to store perishable foods at room temperature. J. Food Eng. 2017, 193, 76-85. [CrossRef]

(C) 2019 by the author. Licensee MDPI, Basel, Switzerland. This article is an open access article distributed under the terms and conditions of the Creative Commons Attribution (CC BY) license (http://creativecommons.org/licenses/by/4.0/). 